\title{
Evaluation of The Role of Transrectal Fine Needle Aspiration As A Diagnostic Modality in The Diseases of Prostate with Review of Literature
}

\author{
Ansar A Khan ${ }^{1}$, Prashant K Jain ${ }^{1}$, Binjul Juneja ${ }^{1}$, Mohammad Talha ${ }^{1}$, Ghazala Mehdi ${ }^{1}$ \\ Kafil Akhtar ${ }^{1 *}$ and Gahlaut YS ${ }^{2}$ \\ ${ }^{1}$ Department of Pathology, Jawaharlal Nehru Medical College, Aligarh Muslim University, Aligarh. (U.P)-India. \\ ${ }^{2}$ Department of General Surgery, Jawaharlal Nehru Medical College, Aligarh Muslim University, Aligarh. (U.P)-India.
}

\section{ABSTRACT}

Introduction: Transrectal fine needle aspiration cytology is feasible, reliable and highly sensitive diagnostic tool for the diagnosis of prostatic diseases. It mostly involves the elderly men, whose population is increasing in our country with the demographic shift of longitude.

\begin{abstract}
Aims and Objectives: To evaluate the sensitivity, specificity and positive productive value of transrectal fine needle aspiration cytology in addition to other advantages so that it could be accepted as a primary screening tool in the selection of the patients for biopsy and treatment of prostatic lesions.
\end{abstract}

Material and Methods: Transrectal FNAC was performed in 49 patients, in clinically diagnosed cases of prostate diseases. Histomorphology was also carried out.

Results: Satisfactory smears could be obtained in $93.9 \%$ cases on first aspiration. The diagnostic accuracy for inflammatory disease was highest $(100.0 \%)$, followed by malignant $(88.8 \%)$, and benign lesions $(82.9 \%)$, with a positive predictive value of $100.0 \%$ for malignancy of the prostate. False positivity was seen in $2.09 \%$ and false negativity in $11.2 \%$ cases.

Conclusions: Transrectal FNAC is an accurate, sensitive, highly specific procedure with a high positive predictive value with negligible complication with an additional advantage of possible assessment of prognosis.

Keywords: Transrectal FNAC, Franzen Technique, Prostatic Carcinoma.

\section{Introduction}

Transrectal fine needle aspiration is very quick safe, feasible, atraumatic, highly accurate and economical procedure with negligible complication for the diagnosis of prostate disease, particularly the malignancy. A précised area is required for aspiration; further it does not require anesthesia or any bowel preparation. Therefore it can easily be carried out in the out-patients department of a hospital and in a private clinic.

Ferguson introduced an intraperineal prostatic aspiration technique, which was riddled with many complications. ${ }^{1}$ Later Franzen et al evolved a refined technique by adopting a transrectal approach, with a self- made instrument, Kifa syringe to make the procedure safer. ${ }^{2}$ Later, Esposti, Zajicek, Ekman et al and Alfthan et al utilized this technique and advocated its reliability, safety, sensitivity, specificity and other advantages as compared to intraperineal FNAC and biopsy. ${ }^{3-6}$

But for the next two decades it was not much accepted in the United States. Klnie and Kannan in 1977 found excellent results of the Franzen technique. ${ }^{7}$ India was sluggish in accepting this procedure, on account of reluctance on the part of general pathologists and lack of experience of the clinician and urologist. Hence very few reports are available from India till end of the $20^{\text {th }}$ century.

\section{Material and Methods}

This collaborative study was performed in the departments of Surgery and Pathology of JN Medical College, AMU, Aligarh on 49 patients of provisionally diagnosed cases of prostatic disease with the help of a lumber puncture needle of 22/23G. Fine needle aspiration cytology was performed by the Franzen technique from hard and nodular areas of the prostate. In each case 2-5 passes per aspiration were carried out and total material obtained was spread on 3-4 grease free slides. All the slides, which were for Pap and $\mathrm{H}$ and $\mathrm{E}$ staining were immediately fixed in $95 \%$ alcohol except one which was air dried for MGG stain. Cytological diagnosis was based on the criteria laid down by Koss. ${ }^{8}$ Histopathological tissue was obtained by trucut biopsy or excision of the prostate. Paraffin blocks were prepared of the tissue after fixation in $10 \%$ formalin. $3-5 \mu$ thick sections were cut and stained with VG stain. Histopathological 
tissue was obtained in 44 cases and its correlation with cytology could be done in 40 cases only.

\section{Observations}

In our study, the youngest patient was 25 years old and the oldest was 85 years of age, with the mean age of 59.16 years. Clinically most of the patients presented with features of prostatism. There was increased frequency of micturition in $75.0 \%$, followed by acute retention of urine in $73.5 \%$, thinning of urinary stream in $65.3 \%$, hesitancy in $55.6 \%$, urgency in $42.0 \%$ and haematuria in $12.2 \%$ patients.

The clinical grading by per rectal examination revealed grade III enlargement of prostate in 23 cases (46.9\%), grade II in 18 cases $(40.8 \%)$ and grade I in 8 cases $(14.3 \%)$. The rectal mucosa was mobile in $47(95.5 \%)$ cases and fixed in $2(4.1 \%)$ cases. In grade III cases, the surface of prostate was smooth with firm consistency in 15 cases, and hard and nodular in 8 cases. In grade II cases, the surface was smooth with firm consistency in 13 cases and hard and nodular in 5 cases. All the cases of grade I had smooth surface, with soft to firm consistency. (Table 1)

Out of the 32 clinically diagnosed benign lesions, $26(81.3 \%)$ were found to be benign and 1 (3.1\%) each malignant, suspicious of malignancy and inflammatory while $3(19.4 \%)$ cases were unsatisfactory on cytological examination. Among the 8 clinically diagnosed malignant cases, $7(87.5 \%)$ were found to be malignant and $1(12.3 \%)$ benign on cytological examination. Smears from malignant cases showed cohesive clusters and sheets of highly atypical cells with marked anisocytosis and anisonucleosis, with overlapping of nuclei and crowding, with acinar formation at places (Figure 1 and 2). The 4 cases of inflammation were found to be suffering from prostatitis. The rest of the 5 cases which were clinically highly suspicious of malignancy revealed $3(60.0 \%)$ as benign and 1 each $(20.0 \%)$ as malignant and highly suspicious of malignancy on cytological examination. (Table 2)

Out of the clinically diagnosed 49 cases of prostatic diseases, 35(71.4\%) cases were diagnosed as benign and $9(18.4 \%)$ cases as malignant on histopathological examination. Out of the remaining 5 cases, 4 were already confirmed on FNAC as prostatitis and 1 did not allow any surgical procedure. Out of the 5 cases highly suspicious of malignancy clinically, $1(20.0 \%)$ was malignant and $4(80.0 \%)$ benign on histopathology. (Table 3 )

The overall diagnostic accuracy was $85.4 \%$ in our study. The diagnostic accuracy in malignancy was $88.8 \%$ with a false negative rate of $11.1 \%$ in our study. In the benign lesions, the diagnostic accuracy was $82.9 \%$ with false negative rate of $11.2 \%$ and false positive rate of $2.9 \%$. (Table 4) The unsatisfactory smears were $6.2 \%$. The clinically diagnosed 13 cases of malignancy including the suspicious cases, revealed a sensitivity of $88.9 \%$ and specificity of $100.0 \%$ on FNAC. In the clinically diagnosed 32 patients of benign hypertrophy, FNAC showed a sensitivity $92.9 \%$ and specificity of $75.5 \%$. The statistical analysis showed a positive predictive value of $100.0 \%$ in malignancy and $92.3 \%$ in benign prostatic hypertrophy on FNAC. A negative predictive value was $80.0 \%$ in malignant disease and $60.0 \%$ in the benign disease in our study. (Table 5)

Table I: Correlation of Cytological and histopathological diagnosis of the clinical grades of enlarged prostate.

\begin{tabular}{|c|c|c|c|c|c|c|c|c|}
\hline $\begin{array}{c}\text { Grade III Enlarged } \\
\text { prostate }\end{array}$ & $\begin{array}{l}\text { Smooth, Firm } \\
\text { and closed }\end{array}$ & Diag & BPH & $\begin{array}{l}\text { Suspicious of } \\
\text { malignancy }\end{array}$ & Malignant & Prostate & Unsatisfied & Total \\
\hline & & Cyto & 12 & - & 11 & 1 & - & \multirow[b]{2}{*}{15} \\
\hline & & Histo & $12+1$ & - & 11 & - & - & \\
\hline & Hard \& Nodular & Cyto & 3 & 1 & 4 & - & - & \multirow[b]{2}{*}{8} \\
\hline & & Histo & $3+1$ & - & 4 & - & - & \\
\hline \multirow{4}{*}{$\begin{array}{c}\text { Grade II } \\
\text { Enlarged prostate }\end{array}$} & \multirow{2}{*}{ Smooth \& firm } & Cyto & 9 & - & 1 & - & 3 & \multirow[b]{2}{*}{13} \\
\hline & & Histo & $9+3$ & - & 1 & - & - & \\
\hline & \multirow{2}{*}{$\begin{array}{l}\text { Hard and } \\
\text { Nodular }\end{array}$} & Cyto & $3+1$ & - & 1 & - & - & \multirow[b]{2}{*}{5} \\
\hline & & Histo & 3 & - & 11 & - & - & \\
\hline \multirow{2}{*}{$\begin{array}{l}\text { Grade I Enlarged } \\
\text { prostate }\end{array}$} & \multirow{2}{*}{$\begin{array}{l}\text { Smooth and } \\
\text { Soft }\end{array}$} & Cyto & 2 & 1 & 1 & 4 & - & \multirow[b]{2}{*}{8} \\
\hline & & Histo & $2+1$ & - & - & - & - & \\
\hline
\end{tabular}


Table 2: Correlation of Clinical and Cytopathological Diagnosis.

\begin{tabular}{|c|c|c|c|c|c|c|}
\hline \multirow{2}{*}{$\begin{array}{c}\text { Clinical } \\
\text { Diagnosis }\end{array}$} & \multirow{2}{*}{$\begin{array}{c}\text { Total No of } \\
\text { Cases }\end{array}$} & $\begin{array}{c}\text { Cenign } \\
(\%)\end{array}$ & $\begin{array}{c}\text { Malignant } \\
(\%)\end{array}$ & $\begin{array}{c}\text { Inflammatory } \\
(\%)\end{array}$ & $\begin{array}{c}\text { Suspicious of } \\
\text { malignancy (\%) }\end{array}$ & $\begin{array}{c}\text { Unsatisfactory } \\
(\%)\end{array}$ \\
\hline Benign & 32 & $26(81.3)$ & $1(3.1)$ & $1(3.1)$ & $1(3.1)$ & $3(19.4)$ \\
\hline Malignant & 8 & $1(12.3)$ & $7(87.5)$ & - & - & $=$ \\
\hline Inflammatory & 4 & - & - & $4(100)$ & - & $=$ \\
\hline $\begin{array}{c}\text { Suspicious of } \\
\text { Malignancy }\end{array}$ & 5 & $3(60)$ & $1(20)$ & - & $1(20)$ & - \\
\hline Total & 49 & 30 & $\mathbf{9}$ & $\mathbf{5}$ & $\mathbf{2}$ & \\
\hline
\end{tabular}

Table 3: Correlation of Clinical and Histopathological Findings.

\begin{tabular}{|c|c|c|c|c|}
\hline \multirow{2}{*}{ Clinical Diagnosis } & \multirow{2}{*}{ Total No of Cases } & \multicolumn{3}{|c|}{ Histopathologic Impression } \\
\cline { 3 - 5 } & & Benign (\%) & Malignant (\%) & Inflammatory (\%) \\
\hline Benign & 32 & $31(96.9)$ & - & $1(3.1 \%)$ \\
\hline Malignant & 8 & - & - & $4(100)$ \\
\hline Inflammatory & 4 & - & $1(20)$ & - \\
\hline Suspicious of Malignancy & 5 & $4(80)$ & $\mathbf{9}$ & $\mathbf{5}$ \\
\hline TOTAL & $\mathbf{4 9}$ & $\mathbf{3 5}$ & & \\
\hline
\end{tabular}

Table 4: Comparative diagnostic accuracy of FNAC and Biopsy in Carcinoma of Prostate.

\begin{tabular}{|c|c|c|c|c|}
\hline Authors & Year & Total No. of cases & $\begin{array}{c}\text { Diagnostic Accuracy } \\
\text { on FNAC }\end{array}$ & $\begin{array}{c}\text { Diagnostic Accuracy } \\
\text { on Biopsy }\end{array}$ \\
\hline Esposti & 1974 & 350 & 97.0 & 96.0 \\
\hline Ekman & 1967 & 100 & 90.0 & 90.0 \\
\hline Alfthan et al & 1970 & 220 & 95.0 & 88.0 \\
\hline Epstein & 1976 & 118 & 86.4 & 85.6 \\
\hline Kline\& Kannan & 1982 & 540 & 92.0 & 98.6 \\
\hline Hermida et al & 2001 & 58 & 94.0 & 88.0 \\
\hline Saleh et al & 2005 & 60 & 91.7 & 89.7 \\
\hline Pantola et al & 2012 & 78 & 95.2 & 85.4 \\
\hline Our Study & & 49 & 88.8 & \\
\hline
\end{tabular}

Table 5: Evaluation of Trans-rectal FNAC in Prostatic Carcinoma with Statistical Correlation.

\begin{tabular}{|c|c|c|c|c|c|c|c|}
\hline Authors & Year & $\begin{array}{c}\text { Total } \\
\text { No. of } \\
\text { Cases }\end{array}$ & $\begin{array}{c}\text { Cyto- } \\
\text { histological } \\
\text { correlation (\%) }\end{array}$ & Sensitivity (\%) & $\begin{array}{c}\text { Specificity } \\
(\%)\end{array}$ & $\begin{array}{c}\text { False } \\
\text { Negative } \\
(\%)\end{array}$ & $\begin{array}{c}\text { False } \\
\text { Positive } \\
(\%)\end{array}$ \\
\hline Ekman & 1967 & 100 & 76.0 & 90.0 & 80.0 & 7.2 & 2.0 \\
\hline William et al & 1967 & 51 & 76.0 & 96.0 & 100 & 4.0 & 0 \\
\hline Alfthan et al & 1970 & 220 & 88.0 & 95.0 & 96.5 & 6.4 & 1.4 \\
\hline Lin et al & 1972 & 27 & 71.0 & 81.5 & 100 & 5.0 & 0 \\
\hline Kline \& Kannan & 1982 & 416 & 87.0 & 88.0 & 91.0 & 12.0 & 8.0 \\
\hline Melagrana et al & 1982 & 87 & 80.0 & 80.0 & 92.0 & 20.0 & 9.0 \\
\hline Mondal et al & 1990 & 126 & 98.4 & 98.4 & 100 & 1.6 & 0 \\
\hline Hermida et al & 2001 & 497 & 96.0 & 96.0 & 96.0 & 4.0 & 2.0 \\
\hline Saleh etal & 2005 & 60 & 91.7 & 88.0 & 93.0 & 4.8 & 7.5 \\
\hline Tariq et al & 2007 & 56 & 93.0 & 94.0 & 96.0 & 3.3 & 0 \\
\hline Pantola et al & 2012 & 121 & 95.2 & 98.7 & 98.7 & 4.8 & 1.6 \\
\hline Reddy and Rani & 2016 & 27 & 84.2 & 84.0 & 97.0 & 3.2 & 4.2 \\
\hline Our Study & & 49 & 96.7 & 90.9 & 87.8 & 11.2 & 2.9 \\
\hline
\end{tabular}




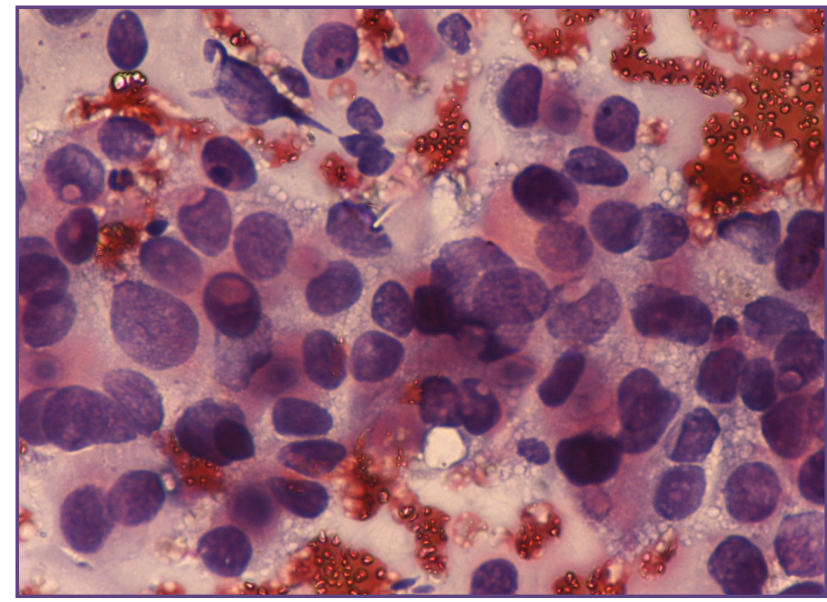

Fig. 1: Fine needle aspiration cytology of the prostatic mass showed cohesive clusters of highly atypical cells with marked anisocytosis and anisonucleosis, with acinar formation at places. Haematoxylin and Eosin $\mathrm{x} 40 \mathrm{X}$.

\section{Discussion}

A better health care system is available now all over the world. Gawandi reported in his recent book," Being MORTAL" that progress in medicine and public health is an incredible boon and people live long. ${ }^{9}$ Unfortunately in India prostatic diseases in elderly men is increasing with the demographic shift of longevity.

The incidence of carcinoma of the prostate and its mortality rate varies worldwide. ${ }^{10,11}$ In UK it is the sixth most common neoplasm. ${ }^{12}$ In USA alone, it is the third most common cause of cancer death in males. ${ }^{13,14}$ From USA and Australia, it has been reported to cause 20\% morbidity and $11-20 \%$ mortality. ${ }^{13,14}$ Later Joseph and Fajers reported carcinoma prostate to be the second leading cause of cancer death. ${ }^{15}$ In Iraq, it was registered to be one of the commonest among the ten cancers in males. ${ }^{15}$ Korean report shows a recent increase in the incidence of cancer prostate. ${ }^{16}$ Prostatic cancer is presently the fifth most common newly diagnosed malignancy in Korean men. ${ }^{17}$ The incidence India is reported as 6.8 per one lac, which is increasing now. ${ }^{18}$

The age group involved in the west is mostly $7^{\text {th }}$ or $8^{\text {th }}$ decade, while in India, most of the cases are seen in the $6^{\text {th }}$ decade of life. ${ }^{13,19}$ In our study, the average age of the patients was 59.2 years, findings similar to Mandhani and Reddy \& Rani. ${ }^{18,19}$ The difference of age of affliction between India and the west can easily be explained on the basis of shorter life span in India as compared to the west. Scadino et al found on autopsy of elderly men between 75- 93 years, that occult carcinoma unclinically diagnosed was found in $80.0 \%$ cases over the age of 80 years. ${ }^{20}$ They

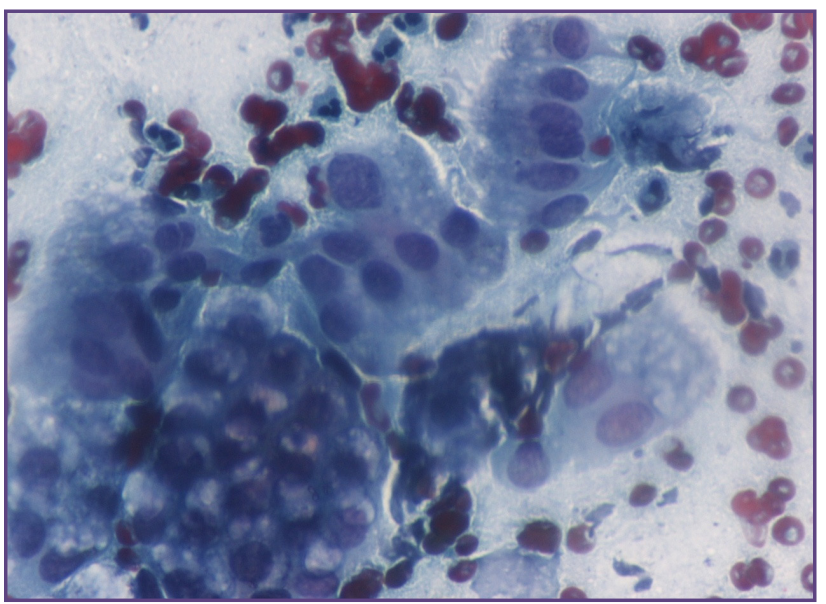

Fig. 1: Fine needle aspiration cytology of the prostatic mass showed cohesive clusters of highly atypical cells with marked anisocytosis and anisonucleosis, with acinar formation at places. Haematoxylin and Eosin $\mathrm{x} 40 \mathrm{X}$.

further observed that autopsy cases included one-fifth potentially malignant tumors, which on manifestation could have been fatal. But four-fifth would have remained as occult carcinoma. This indicates that early detection of cancer prostate is of paramount importance, as it may be curative, like cervical cancers in females. The most common clinical presentation in our study was increased frequency of micturition, followed by acute retention of urine; these findings are comparable to reports of Reddy and Rani. ${ }^{19}$

Early detection of prostate cancer requires a frequent and skillful digital rectal examination (DRE), with a high index of suspicion for the induration and nodules. ${ }^{21}$ Thirteen out of 49 cases in our study were found to have hard and nodular prostate on digital rectal examination (DRE). Among these, 7 were found malignant but only $6(46.7 \%)$ could be confirmed by biopsy. Similarly Jewett in 211 cases and Goodwin in 301 cases on DRE could demonstrate the presence of malignancy on aspiration in $57.0 \%$ and $50.0 \%$ cases respectively. ${ }^{22,23}$ The hard and nodular prostate is one of the foremost clinical manifestation of cancer, but it may not be pathognomonic of malignancy in every case. ${ }^{22,23}$ Later with more experience in the technique and better knowledge of the criteria of malignancy in fine needle aspiration cytology, Mondal et al and Tariq et al could diagnose $96.0 \%$ and $93.0 \%$ cases on DRE respectively. ${ }^{24,25}$

Planelles et al and Gomez et al observed the presence of malignant cells in FNAC of all the $72(100 \%)$ cases suspicious of malignancy on DRE, with PSA levels 20$30 \mu \mathrm{g} / \mathrm{ml} .{ }^{26,27}$ Reddy and Rani could diagnose only $84.0 \%$ of their 27 cases on DRE. ${ }^{19}$ They reported a high false negative report of $15.8 \%$, which probably may be the 
reason for low diagnosis. This can be suggested that cases with induration and nodulation on DRE with suspicion of malignancy can help in the selection of patients for FNAC and core biopsy. We can affirm by our long experience of four decades in cytopathology that if malignant cells are seen in the smears, then confirmation by biopsy is not a necessity. Ekman et al also emphasized that a positive cytological diagnosis of cancer should be regarded as unequivocal evidence of a malignant growth. ${ }^{5}$ Suhrland et al and Kher et al also opined that a positive cancer diagnosis by cytology even if not confirmed by biopsy, is still an indication of malignancy of the prostate..$^{28,29}$ But a classical biopsy is the final arbitrator for doubtful or suspicious cases. ${ }^{28,29}$ Although a classical biopsy is the final arbitrator for doubtful or suspicious cases, Johnson \& Fajers, Hock et al and Wahi tried to evaluate cytological diagnosis of smears of prostatic secretions obtained by massage, in search of early detection of cancer prostate, with a success of $61-81 \%$. 15,30,31 Prof Wahi emphasized this technique as a method of choice, when one of his cases showed malignant cells in the smears of prostatic secretions, with twice negative tissue biopsy, which later was proven after radical resection. ${ }^{31}$

Although this smear technique found optimism, but later it was found unsuitable for the diagnosis of prostate malignancy as compared to the classical reliable histomorphological study of incisional and excisional biopsy. The perineal and transrectal biopsies of the prostate claimed to provide better results. ${ }^{16,21}$ But perineal and transrectal biopsies were plagued with multiple complications. ${ }^{21,24}$ Anderson et al combined the transrectal biopsy by a large bore needle (veenema) in 379 cases with transrectal fine needle aspiration in 69 cases $^{32}$ They reported complications of biopsy like haemorrhage, deep vein thrombosis and febrile illness in $19.5 \%$ cases. Puigvert et al found perineal tumor implantation following needle biopsy of prostatic masses with large bore needles (Turkle, Vim Silverman Needle, Veenema, Malinger, Blanchard). ${ }^{33}$ Ekman et al in 100 cases and Alfthan et al in 220 cases reported no complications of transrectal biopsies. ${ }^{5,6}$ But Bissada et al and Thompson et al found it responsible for high frequency of infections. ${ }^{34,35}$ Volter and Zeiglar reported fever as high as $39^{\circ} \mathrm{C}$ for 12 days in $9(0.9 \%)$ cases and bloody urine in $15(1.5 \%)$ in a total of 1020 cases studied by transrectal aspiration. $^{36}$

Eaton performed blood culture in 20 patients 10 minutes after the transrectal biopsy and found positive in 17(95.0\%) cases. ${ }^{37}$ Hosking et al obtained blood culture in 19 patients one hour and in 14 patients 5 minutes after aspiration. ${ }^{38}$ Only 2 cases out of 33 were found to be positive for staphyllococcus epidermidis. ${ }^{38}$ This suggested that transrectal FNAC even without bowel preparation or antibiotics does not cause bacteremia.

In search of early detection of prostate carcinoma, surgery on a normal elderly person was a real tragedy. Therefore improvement in diagnostic tool as franzen transrectal aspiration was a real boon. It was found to be feasible, reliable, quick, easy, less traumatic and safe with high diagnostic accuracy, ranging from $90-96 \%$, with an experience of 20 years in transrectal aspiration. ${ }^{3}$ The comparative study of diagnostic accuracy of fine needle aspiration and core biopsy in carcinoma prostate showed a higher diagnostic accuracy of FNAC as compared to biopsy in our study. Al-Ababi compared the results of cytology and histology and found that the sensitivity of fine needle aspiration was $98.0 \%$ as compared to core biopsy sensitivity of $96.0 \%$ in carcinoma prostate. ${ }^{39}$ Similar observations have been reported by Ekman et al, Alfthan et al, Kline et al, Tariq et al, Al Ababi, Narayan et al, M Cho et al, Ljung et al, Chodak et al, Deliveliotis et al, Carter, Pantola et al and Saleh et al. ${ }^{5-7,25,39-47}$ But our results were contradictory to the study of William and Ou et al. ${ }^{48,49}$

The evaluation of transrectal FNAC in prostatic carcinoma in our study showed a sensitivity of $88.8 \%$, which is comparable to the findings by Saleh et al and Kaur et al, who have reported it to be $88.0 \%$ and $90 \%$ respectively. ${ }^{47,50}$ Our study showed a positive predictive value of $100.0 \%$ in malignancy and $92.3 \%$ in benign prostatic hypertrophy on FNAC. Pantola in their 121 cases reported positive predictive value of $97.6 \%$ and negative predictive value of $97.5 \%$, with a sensitivity of $95.2 \% .{ }^{46}$ Hermida et al in their 497 cases showed a positive predictive value of $91.0 \%$ and negative predictive value of 93.0 with $96 \%$ sensitivity. ${ }^{14}$ Bently et al in their 170 cases found sensitivity of $88.0 \%$ and positive predictive value of $78.8 \% .^{51}$ The positive predictive value is the probability that the patient had the disease, when the test was called positive, but a negative predictive value indicates that the patient is disease free. The predictive values (PV) are dependent on the criteria and prevalence of malignancy in the population. Thus PV are an aid to the urologists in deciding as to what importance should be assigned to the reported results. These reports help the urologists in making the clinical decisions, based on the FNAC findings provided by the cytopathologists. It has been observed that the clinicians experience with expertise in Franzen technique and interpretation of the cytological findings will be a real help in the medical care of the patients. 
The efficiency is the frequency with which all cases are correctly classified as malignant or benign. Although it is accepted that FNAC by franzen technique gives excellent results by the combination of a clinician and a competent pathologists, still some limitations in the form of false negative and false positive diagnosis have been observed. ${ }^{28,45}$ False negative diagnosis in our study $11.2 \%$ which was equivalent to Kline and Kannan and Ingle and Ingle, who reported $12.0 \%$ and $12.8 \%$ respectively. ${ }^{7,10}$ Melagrana et al and Lin et al reported higher false negative cases as $20.0 \%$ and $29.0 \%$ respectively. ${ }^{52,53}$ As most of the clinicians are aware of the hazards which is inherent, mostly on account of insufficient smears and are always prepared to repeat the aspiration, if they clinically suspect malignancy. Further it can be confirmed on long follow up, on repeat aspiration. The false positive diagnosis is more a hazard in cytologic preparations, which may be due to misinterpretation of atypical cells. Further it could be due to contamination from rectal mucosa, dysplasia and therapy induced alterations. ${ }^{51}$ Cytodiagnosis can be improved by the collection of sufficient material, which is possible with larger number of passes per aspiration. Besides, more material can be obtained from the peripheral part of tumor which is soft and cellular as compared to the hard center. Multiple passes are not possible with biopsy needle. Insufficiency report varies from $1.3-6.4 \%$ in most of the studies. ${ }^{48,54}$ Our insufficiency in the total 49 cases was only $6.2 \%$. Melagrana after repeat aspiration could increase sensitivity of carcinoma cases from $77.0 \%$ to $80.0 \%{ }^{52}$

In cytology the borderline cases between benign atypia and malignancy in cell groups is difficult to interpret. ${ }^{55}$ The problem of whether these false positive reports are in fact due to small malignancies or due to misinterpretation of atypical prostate cells, can be only answered by long term follow up or repeat aspiration with additional use of imprint cytology. ${ }^{55,56}$ It is noted that lack of knowledge of the special features of atypical hyperplasias, the incidence of which may be upto $49.09 \%$ may lead to error in the interpretation. ${ }^{57,58}$

Gaetani and Trentini described the cytomorphological features of atypical hyperplasia of the prostate, which helped the pathologists to differentiate it from poorly differentiated carcinomas. ${ }^{59}$ Atypical prostate cell is an abnormal cell, with greater activity than ascribed with certainty to reactive changes. ${ }^{59}$ The important features are tumor cell in well spaced clumps in acinar pattern with mild pleomorphism and nuclear moulding disposed on an eosinophilic background of secreted matter, with a finely granular appearance. This cell disposition was a representative of the histologic pattern of atypical hyperplasia, characterized by acini usually bordered by the pseudostratified undifferentiated epithelial cells, showing severe degree of loss of polarity. Another relevant feature was the lack of RNA, which is more in carcinoma than atypical hyperplastic cells, seen under fluorescent microscope after acridine orange stain. ${ }^{59}$

Koss had described these atypical cells as a group of pluri-stratified plugs of epithelial cells of quasi-papillary appearance with fairly regular nuclei, which may arouse suspicion of malignancy. ${ }^{8}$ Gaetani and Trentini were of the opinion that atypical epithelial hyperplasia represents the main pitfall in the cytologic diagnosis of poorly differentiated prostatic carcinoma. ${ }^{59}$ These two lesions are characterized by undifferentiated or poorly differentiated carcinoma cells with several features in common, which leads to false positive diagnosis. Poorly differentiated carcinoma cells are disposed as singly or in small groups with non-uniform irregular nucleus with coarse clumped chromatin and large atypical mitotic figures. ${ }^{59}$

Further the inability to differentiate benign atypia from well differentiated carcinoma was also attributed to low diagnostic accuracy. ${ }^{3}$ To differentiate well differentiated carcinoma from atypia, Esposti described the former as a microadenoma complex with central cytoplasm and a peripheral nuclei and occasional free cells. ${ }^{3}$ Later Epstein pointed that acinar arrangement with stratified arrangement of nuclei bore no relationship to well differentiated carcinoma.${ }^{57} \mathrm{He}$ further emphasized that the following five features of neoplasisa should be observed for the diagnosis of well differentiated carcinoma: 1) loss of polarity 2) presence of nucleoli 3) anisonucleosis 4) moulding of nuclei and 5) acinar arrangement of cells with hyperchromatic nuclei. Though these studies were conducted in different geographical areas, discussions by Geetani of atypia and critical analysis of Epstein of well differentiated carcinoma, did help in arriving at a concurrent and feasible diagnosis. ${ }^{59,57}$

Cytology can be further helped by cell block like biopsy and aided by imprint smear to increase the diagnostic accuracy and sensitivity of the technique. Mohler et al studied the cell block and opined that it can be used as a safeguard against the radical treatment of false positive diagnosis. ${ }^{60}$ It may further help the cytologists in improving the diagnostic accuracy, who are familiar with prostatic histopathology. Another advantage of FNAC is the possible assessment of prognosis of cancer prostate, 
based on cellular pleomorphism. The grades of cancer as evaluated by pleomorphism are favorably comparable to the histologic grading. Esposti in his study on 469 patients by transrectal fine needle aspiration biopsy cytologically graded prostatic carcinoma on the basis of cell differentiation as well differentiated, moderately differentiated and poorly differentiated. ${ }^{3}$ These patients were treated with hormone and the prognostic significance of differentiation grading was evaluated in terms of response to treatment. Diana on her clinico-cytological study on 50 cases of malignancy of prostate showed a stable disease in high cytologic grade and a progressive disease in poorly differentiated grade of cancer. $^{61}$

\section{Conclusions}

FNA cytology is easy, safe, quick and economical technique and can be easily performed in an out-patient clinic by an experienced urologist. The problem of correct diagnosis leading to high sensitivity can now be overcomed by the knowledge of newly supplemented criteria of atypia and well differentiated carcinoma. Further the hurdle of prognosis can be overcome by cytomorphological grading after hormonal treatment with or without orchidectomy by a competent pathologist. Therefore for the diagnosis of prostatic lesions by Franzen's FNAC is an important modality in the armamentarian of the pathologist as well as urologist and should be utilized in primary screening of all prostatic lesions.

\section{References}

1. Ferguson RS. Prostatic Neoplasms- their diagnosis by the fine needle puncture and aspiration. Am J Surg 1930; 9:507511.

2. Franzen S, Giertz G, Zajicek J. Cytologic diagnosis of prostatic tomours by Transrectal aspiration biopsy: a preliminary report. Brit J Urol 1960; 32:193-196.

3. Esposti PL. Cytologic diagnosis of prostatic tumours with the aid of transrectal FNAB - A critical review of 1110 cases and report of morphologic and cytochemical studies. Acta Cytol 1996;10:182-188.

4. Zajicek J. Aspiration biopsy cytology: cytology of infradiaphragmatic organs. Clin Cytol 1979; 7: 129-164.

5. Ekman H, Hedberg K, Pearson PS. Cytological versus histological examination of needle biopsy specimens in the diagnosis of prostatic cancers. BR J Urol 1967; 39: 544-548.

6. Alfthan O, Klintrup HE, Koivuneimi A, Taskinen F. Cytological aspiration biopsy and vim silverman biopsy in the diagnosis of prostate carcinoma. Ann Chirr Gynae Fenn 1970;59: 226-229.

7. Kline TS and Kannan V. Prostatic aspirate: a cytomorphologic analysis with emphasis on well differentiated carcinoma. Diag Cytopathol 1982; 1:13-17.
8. Koss LG. Koss Diagnostic Cytology and its Histologic Basis. 5th Edn, Lippincott Williams and Wilkins Publishers, 2017; pp 912-913.

9. Gawandi A. "Being Mortal" Medicine and what matters in the end. Hamish Hamilton and Penguin Publishers, 1st Edn, 2014: pp1-12.

10. Ingle SP and Ingle RS. The Efficiency of the Serum Prostate Specific Antigen Levels in Diagnosing Prostatic Enlargements. J Clin Diagn Res JCDR 2013; 7(1):82-88.

11. Barentsz JO, Richenberg J, Clements R, Choyke P, Verma S, Villeirs G et al. ESUR prostate MR guidelines. Eur Radiol 2012; 22(4):746-57.

12. Moore CM, Robertson NL, Arsanious N, Middleton T, Villers A, Klotz L et al. Image-guided prostate biopsy using magnetic resonance imaging-derived targets: a systematic review. Eur Urol 2013; 63(1):125-40.

13. Vargas HA, Hötker AM, Goldman DA, Moskowitz CS, Gondo T, Matsumoto $\mathrm{K}$ et al. Updated prostate imaging reporting and data system (PIRADS v2) recommendations for the detection of clinically significant prostate cancer using multiparametric MRI: critical evaluation using wholemount pathology as standard of reference. Eur Radiol 2016; 26(6):1606-1612.

14. Hermida PJ, Ochoa U, Ramos RA, Acost- Bernad I, Vento RJ, Mesa BD. FNAC in the diagnosis of prostatic cancer. Arch Esp Urol 2001; 54:23-33.

15. Johnson $\mathrm{G}$ and Fajers CM. Cancer cells in prostatic secretion. Acta Cher Scand 1950; 90:545-547.

16. Jung KW, Park S, Kong HJ. Cancer statistics in Korea: Incidence, mortality and survival in 2006-2007. J Kor Med Sci 2010; 25:1113-1121.

17. Jung KW, Park S, Won YS. Prediction of cancer incidence and mortality in Korea . Cancer Res Treat 2011; 43:12-18.

18. Mandhani A. Early prostatic cancer- Radical prostatectomy or watchful waiting. The Nat J India 2005;18(4): 23-26.

19. Reddy SD and Rani S. Efficacy of FNAC in early diagnosis of prostatic carcinoma. IAIM 2016; 3(10):100-114.

20. Scadino PT, Weaver R, Hudson MA. Early detection of prostate cancer. Hum Pathol 2011, 23: 231-234.

21. Guinan P, Bush I, Ray V, Rao R, Bhatti R, Veith R. The accuracy of rectal examination in the diagnosis of prostate carcinoma. N Eng J Med 1980; 303: 409-412.

22. Jewitt HJ. Significance of palpable prostatic nodule, JAMA 1956; 160:838-840.

23. Goodwin WE. In Proc. Third Nation Conference. Early case funding of prostate. Ist Ed, Philadephia, Lippincott publishers, 1957; p: 196-199.

24. Mondal C, Ghosh A, Ghosh E. The role of transrectal FNAC in the diagnosis of prostate nodule suspicious of malignancy. Ind J Pathol Microbiol 1990; 33(1): 23-29.

25. Tariq I, Tammana C, Khan KH, Nahar R. Fine needle aspiration cytology of prostatic lesion with histologic correlation. Ibrahim Med Coll J 2007; 1:7-10. 
26. Planelles GJ, Beltran AJ, Alonso HS, Tarim PM, Beamud CM, Gil SM. Value of transrectal FNA in the diagnosis of prostatic carcinoma in elderly patients. Acta Urol Esp 2008; 32(5):485-491.

27. Gomez S, Henry H, William JP. Transrectal Prostatic biopsy. Br Med J 2010; 4: 595-597.

28. Suhrland MJ, Dietch D, Schreber K. Assessment of FNAC as a screening tool of occult prostatic cancer. Acta Cytol 1988; 32: 495-498.

29. Kher AV, Gadkari PR, Munshi MM, Grover SV. Trans rectal FNAC of the prostate. J Cytol 1989; 6: 28-38.

30. Hock EF, Wood FW, Kosinski AA. The Cytologic Detection of Prostatic Carcinoma: Its Clinical Application. J Urol 1950; 63:1081-1085.

31. Wahi PN. Cytologic diagnosis of prostate carcinoma. Natl Cancer Inst Monogr 1979;149:7-11.

32. Anderson L, Jonnnson G, Brunk U. Puncture biopsy of the prostate in the diagnosis of prostatic cancers. Scand J Urol Nephrol 1967; 1: 227-234.

33. Puigvert A, Elizalde C, Maltz JA. Perineal implantation of carcinoma of prostate following needle biopsy- A Case Report. J Urol 1972; 107: 821-827.

34. Bissada NK, Rountree GA, Sulaiman JS. Factors affecting accuracy and morbidity of transrectal biopsy of prostate. Surg Gynae Obstet 1977; 145: 185-188.

35. Thomson PM, Pryor JP, Williams JP, Eyers DE, Dulake C, Skully MF. The problem of infection after prostate biopsy via transrectal approach. Br J Urol 1982: 54: 736-743.

36. Volter $\mathrm{D}$ and Ziegler $\mathrm{H}$. The cytological detection of prostate carcinoma by transrectal needle aspiration. J Urol 1981; 29(5): 98-101.

37. Eaton AC. The safety of transrectal biopsy of the prostate as an outpatient investigation. Br J Urol 1981; 53:144-148.

38. Hosking DH, Paraskevas M, Hellsten OR, Ramsey EW. The cytological detection of prostate carcinoma by transrectal needle aspiration. J Urol 1983; 129(5): 998-1000.

39. Al-Ababi H. Fine needle aspiration biopsy's ultrasound guided transrectal random core biopsy of the prostatecomparative investigation in 240 cases. Acta Cytol 1997; 41: 981-986.

40. Narayan P, Jagodia P, Stein R, Tanagho E. A Comparison of FNA and Core biopsy in the diagnosis and preoperative grading of prostatic cancer. J Urol 1989; 141: 560-563.

41. M Cho, Schimizu K, Kajima O, Yamada H. FNAC in Screening of Prostatic Cancer. Hinyokika Kiyo 1995; 41(5):365-368.

42. Ljung B M, Cherrie R, Kauffman JJ. Fine needle aspiration biopsy of the prostate gland. A study of 103 cases with histologic follow up. J Urol 1986; 135: 955-958.

43. Chodak GW, Steinberg GD, Bibi M, Wied G, Strai FS, Vogelzang NJ. The Role of transrectal aspiration biopsy in the diagnosis of prostatic cancer. J Urol 1986; 135 (2): 299-302.

44. Delliveliotis C, Stavropoulos NJ, Macrychoritis C, Koutsokalis G, Kostakopaulos H. Transrectal needle aspiration versus trans-perineal biopsy in the diagnosis of prostatic cancer. Int Urol Nephrol 1995; 27(2):173-177.

45. Carter HB, Richle RA, Koizumi JH, Amberson J, Vaughan ED. Fine needle aspiration of the abnormal prostate- A cytohistological correlation. J Urol 1986; 138: 294-296.

46. Pantola C, Kala S, Singh PK, Agarwal A, Amit S. A correlative study between transrectal FNAC and histology of the prostate for the detection of prostate carcinoma. J Dent Med 2012; 1:18-20.

47. Saleh AF, Nahar R, Rahman AJ, Salam MA, Islam F. Role of FNAC in the diagnosis of Prostatic lesions with histologic correlation. Bangladesh Med Res Council Bull 2005; 31(3):95-103.

48. William YC, Qu YC, Yang CR, Chang CL, Hwang T. A comparison of transrectal FNAC and biopsy of prostatic lesions. Zhonghus Path J 2002; 50(1):46-51.

49. Qu YC, Yang CR, Tarim PM, Beamud CM. Transrectal FNA in the diagnosis of prostatic carcinoma in elderly patients. Acta Urol Esp 2010; 33(5):485-490.

50. Kaur H, Paul M, Manjari M, Sharma S, Bhasin TS, Mannan R. Ki-67 and p53 immunohistochemical expression in prostate carcinoma: An experience from a tertiary care centre of North India. Ann Path Lab Med 2016; 3(6):509-516.

51. Bentley ME, Mallery WR, Mueller JJ, Anderson MC, Scott AW, Flagel G et al. Acta Cytol 1988; 42(4): 499-503.

52. Melagrana F, Oertel YC, Kwart AM. Prospective controlled assessment of fine needle prostate aspiration. Urol 1982; 19(1): 47-51.

53. Lin B, Davies WE, Harmata PA. Prostatic aspiration cytology.Pathol 1979;11: 607-614.

54. Judith JT., Krishna B, Usha P, Suresh B. Validity of Fine Needle Aspiration Cytology in Diagnosis of Prostatic Lesions and Correlation with Trucut Biopsy. North Am J Med Sci 2014; 7(2): 1-4.

55. Mallik MK and Najma K. Fine needle aspiration cytology of lesions of prostate glands and its correlation with its histopathology. Indian J Sci Res. 2017; 7(2): 97-103.

56. Dhanamjaya RT, Sreelatha V, Hareesh KA. A Study of Prostatic Lesions With Reference To FNAC Evaluation and Histopathology. Dental and Med Sci 2015; 14(2):42-46.

57. Epstein NA. Prostate biopsy- A morphologic correlation of aspiration cytology with needle biopsy. Cancer 1976; 38: 2078-2087.

58. Battaglia S, Barbolini G, Botticelli AR. Early prostate cancer. Morgagni 1974; 7:77-81.

59. Gaetani DCF and Trentini GP. Atypical hyperplasia of the prostate- A pitfall in the cytologic diagnosis of carcinoma. Acta Cytol 1978; 22(6): 483-486. 
60. Mohler JL, Erozan YS, Walsh PC, Epstein IJ. FNA biopsy: A new method for diagnosis of prostatic carcinoma. Cancer 1989; 63: 1846-1855.
61. Diana P, Ouzzane A, Ahmed HU, Emberton M, Montironi $\mathrm{R}$, Presti Jr JC et al. Quantitative tissue analyses of prostate cancer foci in an unselected cystoprostatectomy series. Br J Urol 2012; 110(4):517-519.

*Corresponding author:

Dr Kafil Akhtar, Professor, Department of Pathology, Jawaharlal Nehru Medical College, Aligarh Muslim University, Aligarh. (U.P)-India.

Email: drkafilakhtar@gmail.com

Financial or other Competing Interests: None. 